\title{
Seismic Strengthening RC Structures Approaches
}

\author{
Kaveh Ostad Ali Askari ${ }^{1 *}$, Vijay P Singh ${ }^{2}$, Nicolas R Dalezios ${ }^{3}$ and Theodore C Crusberg ${ }^{4}$ \\ ${ }^{1}$ Department of Civil Engineering, Islamic Azad University, Iran
}

${ }^{2}$ Department of Civil Engineering, Texas A and M University, USA

${ }^{3}$ Department of Civil Engineering, University of Thessaly, Greece

${ }^{4}$ Department of Biology and Biotechnology, Worcester Polytechnic Institute, USA

Received: 㠿 May 24, 2018; Published: 非 June 08, 2018

*Corresponding author: Kaveh Ostad Ali Askari, Department of Civil Engineering, Isfahan (Khorasgan) Branch, Islamic Azad University, Isfahan, Iran, Email: koa.askari@khuisf.ac.ir

\begin{abstract}
The method based on separation of the earth \& structure. In this method applied force will be decreased during earthquake due to separation of structure \& earth by making base of structure or floors flexible and applying energy dampers component \& separator layer usually have a higher natural period than fixed support natural period which cause the acceleration of seismic spectrum to decrease and a kind of short cylindrical seismic cushion with one hole or more and steel plates with stiffen rubber between them are mundane in seismic separators and because of depreciation of energy by seismic separators and this method is used for stiff structures with high and short frequencies with heavy forces but in this technique the use of seismic separator in soft soils due to possibility of equalization of period and exacerbated phenomenon or Resonance isn't recommended and choose period must be far from earth movement period, if it's possible.
\end{abstract}

Keywords: Structure; Earthquake; Seismic Spectrum; Steel Plates

\section{Using Seismic separators}

The benefits of this method are:

a. Producing suitable flexibility at structure.

b. Decreasing drift of floors and Structural and non-Structural failures.

c. Decreasing frequency of structure vibration and decreasing forces of seismic design.

d. Needing less space of structure for performing this strengthening design.

The Corrosion resistance and bearing of high thermal deformations. The isolators are used below or top of the foundation or at the bottom and axe of the columns or in the middle of the column. Use of energy dissipation: this method is based on increasing the damping and decreasing the oscillation amplitude and consequently reducing the seismic response. All types of dampers are friction, hysteresis, metallic, slurry, visco elastic. The main advantage of all of them is the ease of installing. In recent years the use of steel plates (tadas), divergent frames (EBF) and shear panel systems (SPS) have become more popular in Structural applications. Usually dampers are mounted on braces between the braces, the beams, between the walls or between the wall and the beam. Using the combined system of pre-tensioned cables and dampers 8-2 local restorative repair. The critical zone in the $\mathrm{RC}$ frames is the beam-to-column connection, where the shear failure occurs in the connection panel due to the lack of cross reinforcement concrete or steel armor and the use of FRP jackets or pre-tensioned tendons and ... is among the methods of restoring and local reinforcing RC members.

\section{Covering the Columns}

The shear failure of the RC column in the limited shape changes coupled with the loss of lateral load resistance is due to the fact that the shear strength of column related to its bending strength in cyclical and alternative load is more to decrease faster and the 
covering column with jacket also increases the shear strength both the bonding strength is effective and it increases the confinement and its effects on increasing of the ultimate strain of the concrete. The steel cage is constructed of corrugated sections in the longitudinal and transverse steel straps. In practice, the transverse strap is tangled sideways, using special wrenches or pre-heater members. An empty space between the steel cage and the existing concrete is usually filled with anti-shrinkage resistant mortars. It should be noted that the mortar should not have normal cement sand. Due to the agglomeration of the mortar, an early slippage occurs between the surface of the mortar and the concrete, which affects the increase in loading caused by the Confinement, and where we focus on the protection of steel against corrosion and fire, shotcrete would be used.

Accurately, in the above figure, the gap between the base tubes is about $5 \mathrm{~cm}$ and it is to prevent the possibility of axial load bearing of the steel jacket in large lateral deformations and prevent its local buckling [1]. The alignment of the column with thin steel plates is also done these plates are placed at a slight distance from the surface of the column and the space between them is filled with anti-shrinkage mortar. In both methods, the cage and the steel plate have a slight cross section increasing, and against the concrete method which is the most widely used method in the world and in the use of space, it causes fewer disturbances. It should be noted that steel jackets are different with tubes or steel cans filled with Concrete. First, they are designed with interactions of concrete and steel interconnected functions, but in steel jackets between steel plates and concrete there is a gap which fill with anti-slip and contraction filler material, such as pure cement, and passively the concrete confinement property is used while in CFT as soon as Concrete applying load, entering into the enclosing phase [2].

The use of steel wires in its immediate reinforcement, or post tensioned stripped steel, along with crosswise steel, is also a method of reinforcing the pillar. It is a concrete cover and Reinforced plaster that is very similar to a concrete jacket or armor, except that it is made of a shotcrete or mundane plaster. Steel collar systems, in addition to providing confinement for the pillar, have more advantages than common closure sockets, such as:

a. Encapsulation and confinement of concrete coatings and enhancement of the effective surface and the core of the concrete in the ultimate strength.

b. Creating more bending rigidity and providing proper confinement mechanism compared to the closed tight.

c. Having a sufficient width in concrete with concrete column that increases the distance between the steel collars.

d. Finally, by increasing the cross-sectional area compared to the closed ties Increases the shear strength of reinforced concrete column.

Due to the researches carried out, the effect of confinement on circular and elliptic columns is more than square or rectangular columns, so it is recommended to sweeten the rectangular square columns to increase the enclosing effect. Using the circular or elliptical jacket between the pods And reinforced concrete column filled with anti-shrink filler [3]. FRP jackets have the advantage of using and installing quickly in short time, light weight with a good corrosion resistance. It should be considered that if the beam is completely doped with FRP lamination, the possibility of early deboning failure is weak, and this disruption mode occurs in the U-shape and the lateral strip and ductile tapes and adheres to the body of the beam, and the ultimate restraint of the FRP is completely effective in the increasing the resistance, and prefabricated composite jackets, which are usually glued with epoxy adhesive to the level of the reinforced concrete column, and surface preparation is important for the greater involvement of the concrete and the adhesive layer, and this method results in reduced ductility [4].

A method which recently used to increase the shear and seismic strength of the columns Increasing Active and inactive side pressure to overcome the expansion and dilatation of adjoining concrete is applied due to the Poisson phenomenon and force at the location of the clamps to increase the adhesion of concrete and steel is applied. In addition to steel bands, today the composite belt of agamid fiber that is pre-tensioned or post-tensioned is used to increase the enclosing effectiveness [5]. In recent research, instead of using FRP composites and steel plates and other types of column packs such as steel cages, steel bands and concrete armor, steel wire nets can be used to increase ductility, especially the shear failure in short columns The cyclic loading has the advantage of this method compared to a thick reinforced concrete covering with a reinforcing mesh network that has a positive effect on the hardness and shear strength and has a negative effect on the ductility that is used in this method with the equivalent volume of steel and reinforcement coating [6].

Thin armed mortar (Ferrous) can be achieved with higher ductility [7-11]. Regarding the shape, we see that the wide plates of steel are rhizome-shaped and similar to FRP composite fibers have orthotropic behavior, and along the larger diameter of the rhizome there is hardness and high resistance, and it is important to place it on the member's axis. The adhesion and bonding of a wide plate with concrete and mortar is very good and is rolled and flattened, due to the superior performance of the perpendicular forces on the plate, which can cause removing concrete layer of the plate.

\section{New Hybrid System}

Recently Professor J.G. Teng presented the FRP Concrete-Steel Double Skin column as shown in Figure 33, which consists of an internal steel pipe and an outer FRP sheath filled with concrete between them. We are looking carefully at the performance of such a column that does not have the disadvantages of steel tubes such as buckling under pressure due to confinement with concrete pods. The concrete is completely enclosed by FRP coating and its final load capacity and final strain under axial load Intensity increases. 


\section{Strengthening slab Connection-Column}

In this connection, critical structural damage is a breakdown of punch or two-sided cutting because of unbalanced moments. The use of inscriptions or concrete pedestals, steel plates and FRP on both sides of the slab to increase the shear capacity of the dipolebonding reinforcement methods. Strengthening of the beamcolumn joints: armored or concrete pods and twisted or corrugated steel plates, steel jackets, FRP laminates, including reinforcing joints, and increasing the shear strength and ductility, and the fundamental problem in bond reinforcement We are faced with a lack of providing a confinement and it is recommended to use a proper mechanical restraint to prevent bulging and buckling of flat steel plates that are used in reinforcement. Ultimate restraint of FRP slabs is very important in improving the connection to provide the confinement.

\section{Strengthening Concrete Walls and Masonry Materials}

The use of steel strips in masonry materials and concrete walls is recommended for increased ductility and resistance. Today, FRP strips are used for countless benefits such as lightweight and high resistance against light weight, high elasticity modulus, high resistance to stretching, and resistance to moisture and environmental conditions (rust and rot), high flexibility, durability and high stability. They are used to reinforce the walls of concrete and masonry materials. The weaknesses of masonry structures against earthquakes are the incompleteness of the transport route of the load on the walls of the loader, the insufficient shear strength of the wall, the absence of auxiliary collar system and the high expansion of the wall to the outside, irregularity in height, lack of suitable foundation, Irregularity In the plan, the weight of the slab and the lack of integrity and the presence of openings and damages include the creation of horizontal cracks between the walls and ceilings, the formation of vertical joints at the intersection of the walls.

The separation of the external walls from each other and ceiling, collapse outside the wall of the external walls and the roof of the cradle of the wall on its plate, creating cracks in the windows and warping the claw wall, resulting in a reduction in the stiffness and strength of the structure, the cracks at the base of walls and openings, separating or knocking in the orthogonal walls, partial collapse of the walls, and most of the unreinforced masonry walls, the inability to handle the pressure of the conductors, and the length of the work piece, are designed and operated, and are not designed to withstand intra-leaf shear forces and bending outside the plate. The bending strength of URM walls depends on the tensile strength of the mortar and the bonding of the FRP layer to the outer surface of the wall to withstand tensile forces along with the compressive strength of the brick has a significant effect on the increase of the bending strength of the wall.

\section{Conclusion}

By reviewing the general feasibility in general or local renforcement of the reinforced concrete and the effectiveness of the strengthening technique and the ease of the experimental method considering the expected level of performance regarding to the level of risk and its economic justification, Considering the effective parameters, we choose one of the retrofitting methods that several empirical and laboratory models have been presented in the field of retrofitting of reinforced concrete structures, but the numerical and theoretical evaluation is limited due to the incompleteness of nonlinear solution methods, which needs combined laboratory and theory researches due to understanding the behavior of the structure before and after the reinforcement.

\section{References}

1. Jong Wha Bai (2003) Seismic Retrofit for Reinforced Concrete Building Structures. Consequence-Based Engineering) CEB Institute Final Report -Texas University, USA.

2. Jianhua Liu (2006) Rehabilitation of Seismically Deficient Reinforced Concrete Structures-State of the art University of Alberta. An Interdisciplinary Journal.

3. Jack P Moehle State of Research on Seismic Retrofit of Concrete Building Structures in the US" Pacific Earthquake Engineering Research Center University of California, Berkley; US-Japan Symposium and Workshop on Seismic Retrofit of Concrete Structures-State of Research and Practice.

4. Giorgio Monti Seismic. Upgrade of Reinforced Concrete Columns with FRP" University Spienza Roma, Italy.

5. Michael N Fardis (2003) Seismic Assessment and Retrofitting of Existing Buildings According to Euro code 8 Dept. of Civil Engineering of Patras, Greece, Fifth National Conference on Earthquake Engineering, Istanbul, Turkey.

6. Tetsuo Yamkawa, Mehdi Banazadeh, Shogo Fujikawa (2004) Emergency Retrofit of Damaged RC Columns Right after Seismic Attack Using PreTensioned Aramid Fiber Belts $1^{\text {st }}$ Conference on Application of FRP Composite in Construction and Rehabilitation of Structures, Tehran, Iran.

7. Ghassan KAl Chaar, Georgy E Lamb (2002) Design of Fiber-Reinforced Polymer Materials for Seismic Rehabilitation of Infilled Concrete Structures US Army Corps of Engineering-Research and Development Center, USA.

8. Mazzolani FM, Della Corte G, Faggiano B (2017) Full Scale Testing and Analysis of Innovative Techniques for Seismic Upgrading of RC Buildings.

9. Ali Sehat Tabatabaei. Energy Dissipation systems for seismic resistance Iran civil center website.

10. Yamakawa T, Nasrollahzadeh K, Nesheli H Satoh (2003) Seismic Retrofitting of RC Columns Using Restressed Aramid Fiber Belts Fourth International Conference of Earthquake Engineering and Seismology Iran.

11. Sadoughi M, Yarandi M (2003) Saatcioglu Seismic Retrofit of Rectangular Concrete Column with Splice Deficiencies by External Restressing Fourth International Conference of Earthquake Engineering and Seismology, Iran. 
This work is licensed under Creative Commons Attribution 4.0 License

To Submit Your Article Click Here: Submit Article

DOI: 10.32474/TCEIA.2018.02.000137

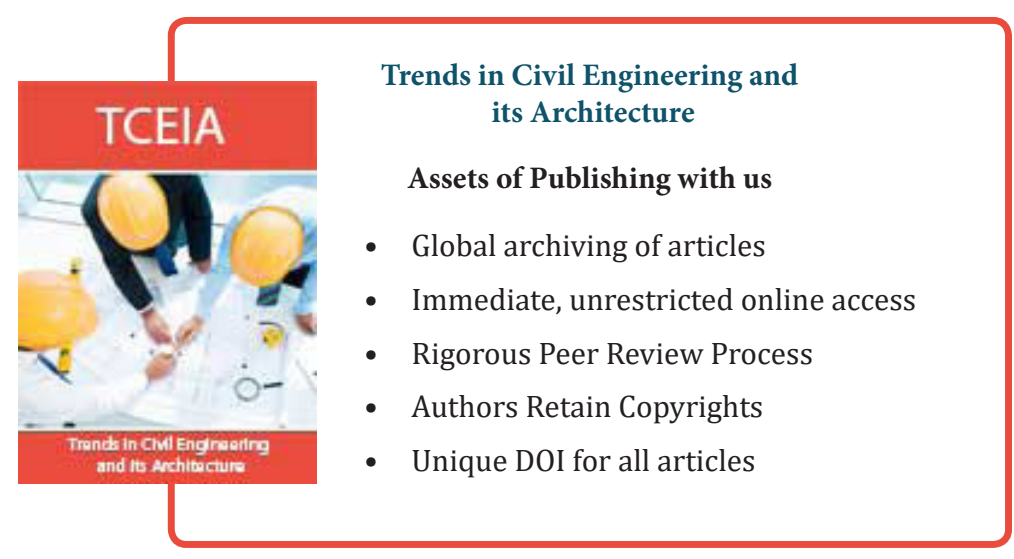

